\title{
From the editor
}

\author{
Harvey S. James Jr.
}

Published online: 5 July 2013

(C) Springer Science+Business Media Dordrecht 2013

I am fascinated by tradeoffs. Maybe it is because of my academic training as an economist. As anyone schooled in economics knows, tradeoffs exist because of the fundamental economic problem. Because resources are scarce, we have to make choices, and with choices there are opportunity costs-what we give up because we choose something else. Simply put, if you want more of "this" then you have to accept less of "that". So, when I read or hear statements that explicitly define tradeoffs, my interest is usually piqued.

I recently read several news articles that described tradeoffs. "Algae bloom turns focus to nutrient use" was one article (Vance 2013, p. 1). In this report, algae blooms in Lake Erie (United States) were attributed to no-till farming. "While no-till cropping reduces soil erosion, ... the practice leaves high levels of phosphorous fertilizers in the upper surface soil, where heavy rainstorms can wash it into waterways that ultimately feed into [lakes]" (p. 3). In other words, if you want less soil erosion, then you have to accept algae blooms. If you don't want algae blooms, then farmers will have to till the soil, and with that comes the risk of soil erosion. Algae blooms or soil erosion. A tough choice.

Another news story reported remarks by US Secretary of Agriculture, Tom Vilsack. Speaking at the April 2013 annual meeting of the North American Agricultural Journalists in Washington, DC, Secretary Vilsack told attendees that "the issue of immigration reform boils down to a simple choice: we can either import farm workers or we can import food" (Griekspoor 2013, p. 24). A nicely described tradeoff. If Americans don't want to import food,

H. S. James Jr. $(\bowtie)$

Department of Agricultural and Applied Economics, University of Missouri, 146 Mumford Hall, Columbia, MO 65211, USA

e-mail: hjames@missouri.edu then they must accept the fact that farmers will have to rely increasingly on immigrant (possibly undocumented) labor to produce the food they eat. If they don't want farmers utilizing immigrant labor, then they have to eat a growing share of imported food. "Americans should not take it for granted that there will always be American-grown food for their table" he said, as quoted in the news report (p. 24). Secretary Vilsack advocates a "workable guest worker program," and appealing to (he believes) an American preference for non-imported food is his way of strengthen his argument.

When considering a reported tradeoff, I usually ask myself "Why is there a tradeoff in this situation?" An economist will tell you that there are really two conditions that create a tradeoff. The first, as stated above, is the fact that we live in a world of scarcity and hence must make choices. The second is that tradeoffs are identified only after holding constant other factors that can affect the problem or choice. For example, holding constant my income, if I want the newest computer tablet, then I will have to forgo something else that I might have used that money for, such as a new suit. Holding constant the amount of time I spend at work, if I want to put more time into preparing for classroom lectures, then I will have less time available to devote to research and publishing. Economists call this ceteris paribus, which is Latin for "other things being equal." Most students are usually introduced to the ceteris paribus principle at the same time they learn about the fundamental economic problem, choice and opportunity costs.

However, in reality "other things" are rarely constant. Therefore, is it necessarily true that we have to accept the specific tradeoffs as they are described by others?

Consider, for instance, Secretary Vilsack's statement that the growing appetite of Americans requires either 
more immigrant labor or more imports. Why? If we need more food to feed American consumers, and if Americans don't want to import food, then why is it the case that the only alternative is to utilize more immigrant labor? Are there no other factors that we can look to that can facilitate increasing food production without the use of immigrant labor? One idea that immediately comes to mind is technology. Indeed, technology has repeatedly been substituted for labor. According to the US Department of Agriculture, in 2009 the level of US farm output was $170 \%$ higher than it was in 1948 (USDA 2013). At the same time, the number of farms declined by $63 \%$ during the last century (Dimitri et al. 2005). How can we get more output from fewer farms and farm worker? The answer: mechanization and technological development. According to Dimitri et al.: "Tractors had essentially replaced animal power by 1970 , and mechanical harvesting of crops (sugar beets, cotton, and tomatoes, for example) became routine by the late 1960s. Advances in plant and animal breeding throughout the century facilitated mechanization and increased yields and quality, enhanced by the rapid development of inexpensive chemical fertilizers and pesticides since 1945," all of which "spurred rapid growth in average farm size, accompanied by an equally rapid decline in the number of farms and in the farm and rural populations" (p. 6). So, if technology was such a driving force for the decline in the number of farms and farm operators and for improved agricultural productivity last century, then why is it ignored in the description of tradeoffs today? To be sure, by holding technology constant we might argue that the appropriate tradeoff is between immigrant labor and imports. But technology is not constant; it is always changing.

Of course, one can argue that removing one tradeoffimmigrant labor versus imported food-by allowing technology to change creates another tradeoff-technology versus people, for instance. That is correct. The fundamental economic problem still remains. But that does not alter the fact that tradeoffs we recognize in the world are the only way to look at the problem. What you see as the appropriate tradeoff may not be the tradeoff that I see.

There are two points to be made here. First, don't accept at face value the tradeoffs or options presented by others. There can be multiple ways of looking at a problem. Sometimes an alternative perspective can illuminate choices and enhance possibilities we have overlooked or are blind to because of prejudice or inexperience. Second, don't presume that things we think are fixed can't or won't change. Sometimes solutions become evident when we consider working with those things we believe are unchangeable.
Fortunately, this issue of Agriculture and Human Values provides insights and perspectives that have the potential of changing how we view the agrifood system. It begins with a paper by Hubbard and Hassanein, who use the case of Roundup Ready Alfalfa to identify specific problems within US regulatory structures designed to promote jointly conventional and organic agriculture. Bonnan-White, Hightower, and Issa identify factors affecting the recruitment and retention of women in Fair Trade cooperatives in their case study of four Palestinian couscous cooperatives. Bain and Selfa study how stakeholders frame the environmental risks and benefits of growing corn for ethanol. Hills, Goldberger, and Jones survey commercial bakers in the US state of Washington to determine how likely they are to adopt locally grown wheat. Thompson and Lockie examine how private food standards affect the vegetable supply chain in Australia, focusing particularly on how such standards affect power relations among stakeholders. Gallaher et al. consider how sack gardening can improve food security for inner-city populations. Myers critiques Petrini's vision of Slow Food as an example of gifting within the alternative food movement. Marquardt, Milestad, and Salomonsson evaluate methods of designating land as fallow for improving farming conditions among smallholder farmers in Peru. Sutherland contrasts organic and conventional farmers in order to determine how economic constraints and cultural factors affect visions of what it means to be a "good farmer." De Barcellos et al. present a study of consumer attitudes towards different pig production systems in China. Seed et al. analyze the effectiveness of integrating food security objectives in local governmental policy initiatives. Finally, Mielby, Sandøe, and Lassen distinguish among five different ways that consumers perceive the naturalness of genetically modified crops are unnatural. Book reviews round out this issue of Agriculture and Human Values.

\section{References}

Dimitri, C., A. Effland, and N. Conklin. 2005. The 20th century transformation of US agriculture and farm policy. Economic information bulletin number 3. Washington, DC: USDA, ERS. http://www.ers.usda.gov/media/259572/eib3_1_.pdf. Accessed 12 June 2013.

Griekspoor, P.J. 2013. Vilsack: Import workers or food. Missouri: Missouri Ruralist.

US Department of Agriculture (USDA). 2013. Agricultural productivity in the US: Overview. http://www.ers.usda.gov/dataproducts/agricultural-productivity-in-the-us.aspx. Accessed 12 June 2013

Vance, A. 2013. Algae bloom turns focus to nutrient use. Feedstuffs: The Weekly Newspaper for Agribusiness, April 8, 1, 3. 